Document downloaded from:

http://hdl.handle.net/10251/65552

This paper must be cited as:

Gisbert Domenech, MC.; Mulet Salort, JM.; Prohens Tomás, J.; Picó Sirvent, MB.; Serrano Salom, R.; Nuez Viñals, F. (2011). Biotechnology for abiotic tolerance and nutritional improvement in selected genotypes of Solanum melongea and cucurbita moschata. Current Opinion in Biotechnology. 22(Suppl 1):S141-S142. doi:10.1016/j.copbio.2011.05.468.

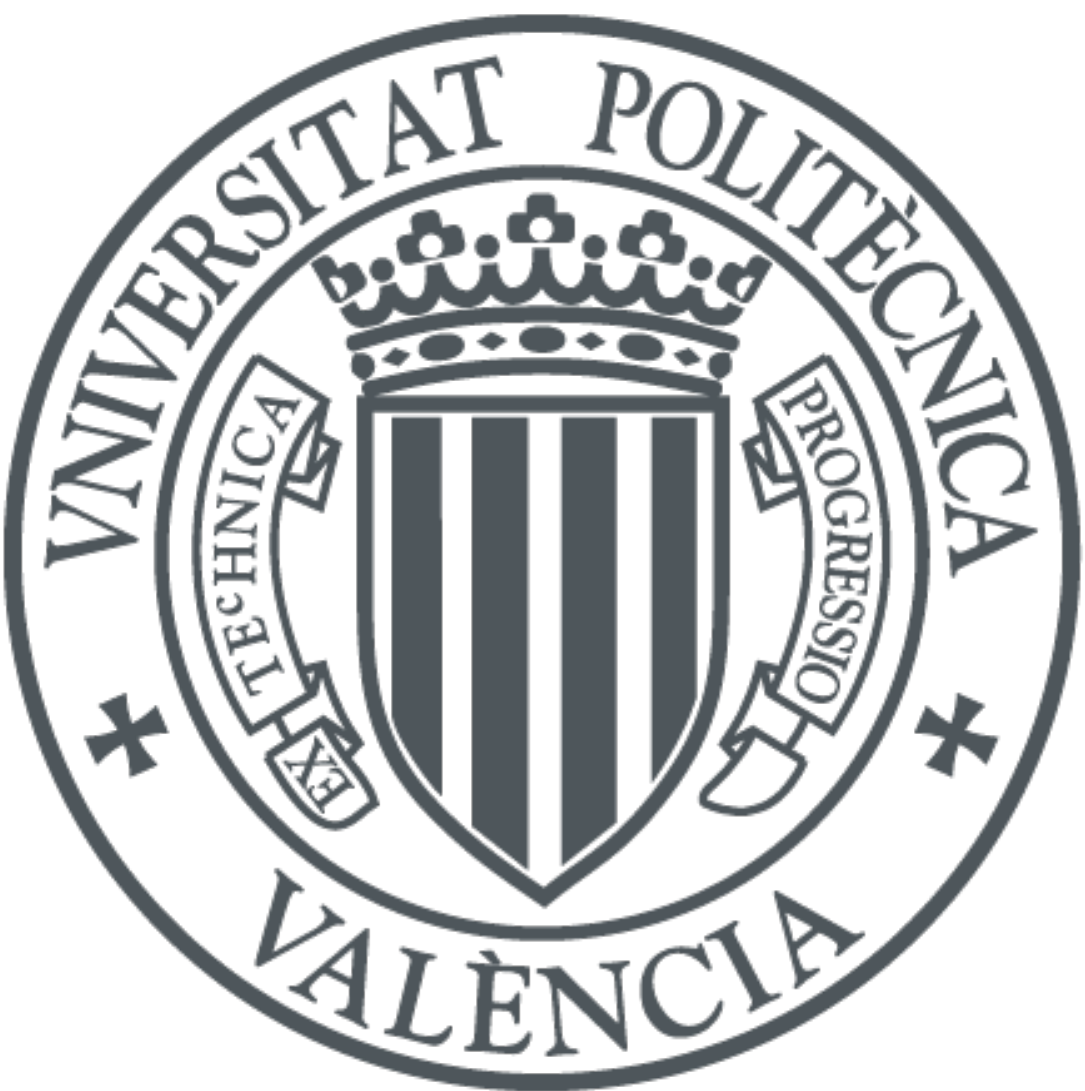

The final publication is available at

http://dx.doi.org/10.1016/j.copbio.2011.05.468

Copyright Elsevier

Additional Information 


\title{
Biotechnology for abiotic tolerance and nutritional improvement in selected genotypes of
}

\section{Solanum melongena and Cucurbita moschata}

\author{
C. Gisbert ${ }^{1 \star}$, J.M. Mulet ${ }^{2}$, J. Prohens ${ }^{1}$, B. Picó ${ }^{1}$, R. Serrano ${ }^{2}$ and F. Nuez ${ }^{1}$
}

1. Institute for the Conservation and Breeding of Agricultural Biodiversity (COMAV) and 2. Instituto de Biología Molecular y Celular de Plantas (IBMCP). Ciudad Politécnica de la Innovación Edificio 8E, Universidad Politécnica de Valencia (UPV), Camino de Vera s/n, 46022 Valencia, Spain

- Presenting author cgisbert@btc.upv.es

Tolerances to biotic and abiotic stresses as well as improving crop nutritional value are currently considered main breeding objectives. The goal of this work is to introduce the BVSAT gene that codifies a serine acetyl transferase, one of the enzymes responsible for the biosynthesis of the essential aminoacids cysteine and methionine, in selected gentoypes. Concretely, into a genotype of Solanum melongena previously selected for its Meloidogyne incognita tolerance, and into a Cucurbita moschata genotype selected for its tolerance to viruses and fungi, and for its fruit quality. This gene has been also related to abiotic stress tolerance. The high influence of genotype on regeneration makes necessary to optimize the transformation protocols for each genotype of interest. We have developed two protocols that have permitted to regenerate transgenic plants from Agrobacterium tumefaciens infected explants. Twelve plants of eggplant and six plants of C. moschata were successfully grown under selective conditions. Insertion of BVSAT gene was confirmed by PCR in these first isolated plants. Evaluation of these materials is underway and may confirm if the introduced gene increases the value of these genotypes.

This work has been funded by Universitat Politècnica de València (PAID 05-10) 